OPEN ACCESS

Edited by:

Pietro Cipresso,

IRCCS Istituto Auxologico Italiano,

Italy

Reviewed by:

Eddy A. Van Der Zee,

University of Groningen, Netherlands

Kenn Konstabel,

National Institute for Health

Development, Estonia

*Correspondence:

Juan C. López

jclopez@us.es

Specialty section: This article was submitted to Quantitative Psychology and Measurement,

a section of the journal Frontiers in Psychology

Received: 07 September 2015 Accepted: 03 February 2016 Published: 19 February 2016

Citation:

Vargas JP, Díaz E, Portavella $M$ and López JC (2016) Animal Models of Maladaptive Traits: Disorders in Sensorimotor Gating

and Attentional Quantifiable Responses as Possible Endophenotypes.

Front. Psychol. 7:206. doi: 10.3389/fpsyg.2016.00206

\section{Animal Models of Maladaptive Traits: Disorders in Sensorimotor Gating and Attentional Quantifiable Responses as Possible Endophenotypes}

\author{
Juan P. Vargas, Estrella Díaz, Manuel Portavella and Juan C. López* \\ Animal Behavior and Neuroscience Lab, Department of Experimental Psychology, Universidad de Sevilla, Seville, Spain
}

Traditional diagnostic scales are based on a number of symptoms to evaluate and classify mental diseases. In many cases, this process becomes subjective, since the patient must calibrate the magnitude of his/her symptoms and therefore the severity of his/her disorder. A completely different approach is based on the study of the more vulnerable traits of cognitive disorders. In this regard, animal models of mental illness could be a useful tool to characterize indicators of possible cognitive dysfunctions in humans. Specifically, several cognitive disorders such as schizophrenia involve a dysfunction in the mesocorticolimbic dopaminergic system during development. These variations in dopamine levels or dopamine receptor sensibility correlate with many behavioral disturbances. These behaviors may be included in a specific phenotype and may be analyzed under controlled conditions in the laboratory. The present study provides an introductory overview of different quantitative traits that could be used as a possible risk indicator for different mental disorders, helping to define a specific endophenotype. Specifically, we examine different experimental procedures to measure impaired response in attention linked to sensorimotor gating as a possible personality trait involved in maladaptive behaviors.

\section{Keywords: dopamine, endophenotype, latent inhibition, mental disorder, prepulse inhibition}

\section{INTRODUCTION}

The criteria used by current diagnostic scales are based on the analysis of external symptoms of the patient. Disorders such as attention deficit with hyperactivity or mental disorders such as schizophrenia are diagnosed based on symptoms that, in many cases, require the patient to evaluate their intensity. This situation creates a serious problem for the diagnosis, given the large amount of subjective information handled by the psychologist or the psychiatrist (Robbins et al., 2012).

The problem of subjectivity and comorbidity in diagnostic errors are, in part, a consequence of the absence of biological markers to facilitate proper classification of the disorder. With relative ease, the diagnostic manuals such as the DSM or ICD propose a continuous change in the criteria for inclusion or exclusion of a disorder due largely to the heterogeneity and complexity of symptoms that define that disorder. These are so complex that patients with different symptoms might have the same diagnosis, a fact that significantly increases the difficulty of providing 
proper treatment. This high comorbidity between various diseases indicates a clear deficiency in the classification system of mental disorders, preventing the identification of valid pathologies (Hyman, 2010). It is possible that the psychotherapeutic and pharmacological failures are largely due to this fact. Note for example that the therapeutic effectiveness of pharmacological treatments reaches approximately 50\% (Wong et al., 2010).

Using a diverse group of pharmacological treatments to relieve disorders such as depression is also an indicator of the disparity of its diagnosis. For example, the use of inhibitors of serotonin reuptake is applied for a specific type of depressive symptoms, which differs from those used under MAO inhibitors or under tricyclics. The differential response of each patient to treatment indicates that disorders included in the same category should be treated with different principles. Alternatively, this phenomenon could be indirectly indicating that different types of disorders within a category may have a different biological basis.

An alternative to this traditional view is the characterisation of endophenotypes. An endophenotype is a quantitative measurable trait associated with a genetic predisposition (Gottesman and Shields, 1972, 1973). In contrast to the symptomatic view of psychopathology, the endophenotype analyses the characteristics that show possible brain vulnerability to suffer a specific type of disorder. The objective is the study and quantification of specific features that reflect a mental disorder associated with a biochemical sign (Hasler et al., 2006; Turetsky et al., 2007). Throughout its long history, the functional study of behavior in the laboratory has provided a number of indicators that could serve as markers for selective expression of the maladaptive behaviors. Applying this model to the field of psychopathology, mental disorders could be considered as extremes at one or both tails of these normal distributions (Miller and Rockstroh, 2013). From this point of view, psychopathology would view disorders as dimensional notions, and not as categories under a binary diagnosis (Hyman, 2010; Frances and Widiger, 2012; Morris and Cuthbert, 2012).

Here, we provide a set of measurable procedures sensitive enough to be used to identify possible endophenotypes developed from animal models. These endophenotypes are based on the correlation between brain processes and measurable responses of a subject that enable us to discriminate between different sets of symptoms, and facilitate new specific therapies. In addition, the evaluation of these traits could facilitate a more objective classification system of psychopathologies.

\section{HOW DOES THE USE OF AN ANIMAL MODEL CONTRIBUTE TO PSYCHOPATHOLOGY CLASSIFICATION?}

The recent developments in genetics and epigenetics allow us to better approach understanding behavior and facilitate the understanding of mental disorders. The fact that some behaviors have a Mendelian basis, suggests the possibility of finding simple mutations that affect behavior in a relatively specific manner. However, there are only a small group of features known as Mendelian traits (or traits 1:1) in relation to genotype. Mental disorders such as depression or schizophrenia are clearly polygenic, or may also be generated by various mutant alleles of the same gene and specific environmental conditions, making the analysis of their causes a complex procedure (Zahn-Waxler et al., 1988; Winokur and Kadrmas, 1989; Kidd, 1997; Moldin, 1997; Owen, 2000; Torrey and Yolken, 2000; Goldman, 2012). Moreover, these illnesses are the result of the interactions of both genetic and epigenetic factors. And although we now have suitable tools for genotype analysis, the fact that these etiological factors -genes and environment- interact to produce similar phenotypes, significantly increases the difficulty to precisely define the specific weight of each one in the generation of behavior (Plomin and Rende, 1991). Identifying what groups of genes may contribute to the expression of a disorder is a long process of molecular genetics. However, the identification of relating groups of genes with specific traits is currently a more achievable goal.

The use of animal models for the study of personality traits, vulnerability to certain disorders or substance abuse dependence is an interesting strategy for developing behavioral protocols in the laboratory. Although in some cases these models could show poor face and predictive validity, the construct validity associated with the etiology or mechanism of the underlying disorder is usually high (O’Donnell, 2011). For example, animal models of schizophrenia have been successful in evaluating risk factors (see Table 1). This fact is crucial in order to develop new pharmacological treatments or genetic therapies. However, the reduced face validity is often a problem when applying to human models.

The development of endophenotypes is one alternative to try to improve this model. Taking advantage of high construct validity, we can develop sensitive tests for quantifying specific traits. Measures such as latent inhibition (LI) or prepulse inhibition (PPI) are, among others, easily quantifiable under controlled conditions in the laboratory. In addition, we can use the advantage of these procedures in a similar way in both animals and humans, and the results are easily extrapolated from an animal model to a human model (Le Pen et al., 2011). While PPI is a very simple procedure seeking to analyze early attentional gating mechanisms, the LI is a learning process related to selective attention and habituation to irrelevant information (Lubow and Gewirtz, 1995; Swerdlow et al., 1996; Braff and Swerdlow, 1997). Animal models indicate that problems in the expression of PPI or LI correlate with cognitive deficits such as working memory or alternation behavior, locomotion activity such as hyperactivity induced by a dopamine receptor agonist, and some negative symptoms also described in pathologies such as schizophrenia (Flagstad et al., 2004; Le Pen et al., 2006; Moore et al., 2006; Hazane et al., 2009). For example, patients with schizophrenia show these symptoms associated with a dysfunctional prefrontal cortex (PfC; Manoach, 2003; Silver et al., 
TABLE 1 | Several animal models have studied schizophrenia.

\begin{tabular}{|c|c|c|c|}
\hline & & MAM & NVHL \\
\hline \multirow[t]{4}{*}{ Executive functions } & Attentional processes & Flagstad et al., 2005; Featherstone et al., 2007 & \\
\hline & Working memory deficits & Flagstad et al., 2005; Hazane et al., 2009 & Chambers et al., 1996; Lipska et al., 2002 \\
\hline & Perseveration & Moore et al., 2006; Hazane et al., 2009 & Marquis et al., 2008 \\
\hline & Recognition deficits & Featherstone et al., 2007 & $\begin{array}{l}\text { Sams-Dodd et al., 1997; Bachevalier et al., } \\
1999\end{array}$ \\
\hline \multirow[t]{2}{*}{ Motivational behavior } & $\begin{array}{l}\text { Increased liability for addictive } \\
\text { behaviors }\end{array}$ & Flagstad et al., 2005 & Swerdlow et al., 2001; Brady et al., 2008 \\
\hline & Responses to stress & Le Pen et al., 2006; Hazane et al., 2009 & Sams-Dodd et al., 1997 \\
\hline Activity & Hyperlocomotion & $\begin{array}{l}\text { Le Pen et al., 2006; Moore et al., 2006; } \\
\text { Penschuck et al., 2006; Hazane et al., } 2009\end{array}$ & Lipska et al., 1993; Wan et al., 1996 \\
\hline $\begin{array}{l}\text { Information filtering } \\
\text { mechanism }\end{array}$ & Sensorimotor gating deficits & $\begin{array}{l}\text { Le Pen et al., 2006; Moore et al., 2006; Hazane } \\
\text { et al., } 2009\end{array}$ & Swerdlow et al., 1995 \\
\hline
\end{tabular}

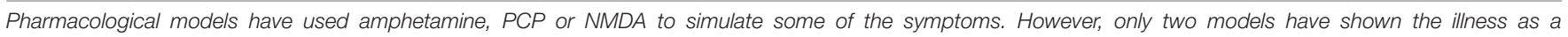

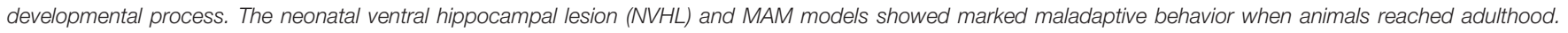

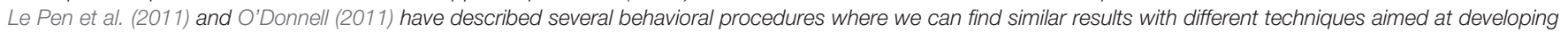
a dysfunctional PfC.

2003; Godsil et al., 2013), therefore, a behavioral test aimed to evaluate PfC function is a useful tool for an accurate differential diagnostic. The knowledge acquired in recent years on the use of a quantifiable measurement of these traits is boosting the development of unified models of diagnosis that include data from all levels, that is: genetics, biochemical, and behavioral levels.

But the question is, how can we contribute to this proposal? Consider, for instance, one of the most complex disorders, schizophrenia. Currently, schizophrenia is an umbrella term for a diverse group of disorders with possibly different etiologies. Focusing on PfC dysfunction, animal research has provided explanatory models to understand the possible development of this mental disturbance (O'Donnell, 2011; Godsil et al., 2013). Procedures aimed to alter gestation and fetal development such as the MAM model (Methylazoxymethanol), or techniques affecting the maturation process of $\mathrm{PfC}$ such as ventral hippocampus lesion in neonates, allow us to experimentally analyze this disorder (Waddington et al., 1999; Bramon et al., 2005; Chambers and Lipska, 2011). Both procedures show a clear PfC dysfunction (Tseng and O'Donnell, 2004, 2007). Cells unit recording studies indicate the possibility of a deficit in inhibitory GABAergic cells. This could be the cause of an excessive release of dopamine cells in the mesocortical system (Tseng and O'Donnell, 2004, 2007; O'Donnell, 2011; Godsil et al., 2013). This could be the reason that PPI or LI could be affected in these animal models and in schizophrenia. Both behavioral processes require an operative PfC for a normal expression. PPI and LI are very sensitive to disturbances in this structure. In this regard, a deficit in one or both processes could be a risk factor. On the whole, the characteristics of a dysfunctional PfC and the impairment in LI and PPI expression could be signs of a specific type of mental disorder, apart from the current model of mental illness where the disorder and its severity are expressed in terms of a scale filled out by the patient or a close family member.

\section{DOPAMINERGIC SYSTEM AS A SIGN OF A POSSIBLE RISK FACTOR}

The function of the dopamine neurotransmitter has attracted great interest because of its relationship with the processes of learning and with several mental disorders such as schizophrenia, depression, ADHT or addiction to a substance of abuse (Robbins, 1992; Feldman et al., 1997; Weiner, 2003; Grace and Sesack, 2010; Simpson et al., 2010; Wise, 2010; Milad and Rauch, 2012; Díaz et al., 2015). The distribution of dopaminergic neurons is abundant in the central nervous system. The midbrain neurons and their efferences to the ventral striatum and PfC play a special role in the learning process (Robbins and Everitt, 1996). Dopaminergic pathways of the ventral tegmental area (VTA) toward the nucleus accumbens (NAc) are closely linked to the motivational processes of learning (Berridge and Robinson, 1998; Berridge, 2007). Many stimulant drugs, such as cocaine or amphetamine, operate in this place, and their function significantly increases the release or reduces the reuptake of dopamine in the system.

Dopamine receptors belong to the G-protein coupled receptors family. All these receptors possess seven transmembrane domains and five subtypes of dopamine receptors according to their molecular characteristics. These have been grouped into two pharmacological families according to the effect produced by agonists and antagonists. D1 family includes the subtypes D1 and D5 receptors. Both stimulate adenylyl cyclase, producing cAMP. On the other hand, D2 receptor family includes the subtypes D2, D3, and D4. These receptors inhibit the formation of cAMP. The D1 receptor is the most abundant in the central nervous system (Missale et al., 1998). The greatest concentration of this receptor is found in the neostriatum, NAc, amygdala, and substantia nigra. However, its affinity for dopamine is relatively low. The D2 receptor is found in high concentrations in the neostriatum (GABAergic neurons) in the NAc and hippocampus, and with a moderate density in the substantia nigra, cerebral cortex, globus pallidus, 
thalamus, and hypothalamus. These data make D1 and D2 receptors specific targets for the study of cognitive, emotional, and motivational disorders. Electrophysiological studies have made important contributions concerning their functional activity in the mesolimbic system (O'Donnell and Grace, 1998; Moore et al., 1999; Grace, 2000; Floresco et al., 2001; Goto and Grace, 2008). These studies are of great relevance given the importance of these receptors in the processes of associative learning. Recent studies have shown that the D2 receptor is located in the projections of both the PfC and the amygdala in the form of autoreceptors (O'Donnell and Grace, 1995; Groenewegen et al., 1999; Goto and Grace, 2008). Specifically, D2 receptors are located in the presynaptic areas with the function of modulating the dopaminergic activity of the VTA over NAc through excitatory projections. That is why this receptor has been linked to the goal directed processes or controlled processes that require high attentional activity (O'Donnell and Grace, 1995; Goto and Grace, 2008). In contrast, the activity of D1 receptors in the mesolimbic system is different than the one described for D2. These are located in the post-synaptic cells of the NAc that receive glutamatergic afferences from the hippocampus and dopaminergic afferences from the VTA (O'Donnell and Grace, 1995; Groenewegen et al., 1999; Goto and Grace, 2008).

Disturbances in this system increase the risk of developing serious mental illness (O'Donnell, 2011; Godsil et al., 2013). Disorders such as schizophrenia have been linked directly to disturbances during brain development associated with the second trimester of pregnancy (Waddington et al., 1999; Bramon et al., 2005). Changes in the dopaminergic sensitivity and in the levels of dopamine or dopamine receptors volume could be the result of this process. Specifically, the family of D2 receptors seems to be more related to the disease process (Grace and Sesack, 2010; Simpson et al., 2010; Wise, 2010; Milad and Rauch, 2012), since the antagonists of these receptors such as haloperidol are effective in reducing symptoms (Lubow and Weiner, 2010). This is the reason why it was suggested a substantial increase of this type of receptors underlies this disorder as shown, for instance, in the studies of post-mortem tissue (Seeman and Nizkik, 1990).

Currently the drug treatment of disorders such as schizophrenia or ADHT act directly on the dopaminergic modulation in the brain. The changes that cause the blockade or stimulation of receptors of this neurotransmitter can be studied in the laboratory. Changes in the sensorimotor gating or selection of relevant stimulus of the environment can be considered as possible quantifiable traits directly related with the level of dopamine or dopaminergic receptors in the mesocortical and mesolimbic system. It is important to emphasize that injuries to PfC produce dopamine dysregulation and deficits in PPI and LI expression.

\section{PPI OF STARTLE RESPONSE. A SENSORIMOTOR GATING MEASURE}

The startle response to an intense stimulus is a reflex behavior that has been described in all mammals studied. This is a fast-twitch of the skeletal muscle that leads to processing environmental stimuli and guiding the attention of the subject to a possible threat. This type of response is interesting because it has been associated with specific genes that appear in schizophrenia and as a possible trait with endophenotypical characteristics. For example, Vaidyanathan et al. (2014) studied the startle blink reflex using a very large human sample. Analyzing the startle response, they found a heritable specific pattern of behavior in the sample. In addition, this trait was associated with candidate genes in the endophenotype of schizophrenia. However, although it is an automatic reaction, the outcome can be modulated by the previous presence of a stimulus of lower intensity, therefore PPI is defined as the attenuation of the startle response to an intense pulse when it is preceded by a lower-intensity prepulse stimulus. When the prepulse is perceived, the mechanism of startle is inhibited and the animal displays a lower response (Graham, 1975; Lüthy et al., 2003; Larrauri and Schmajuk, 2006).

The problems with sensorimotor gating have been linked with the levels of dopamine in the NAc. The NAc integrates information from different structures, and even though dopamine modulation in NAc is dependent on mesocortical and mesolimbic systems (Ellenbroek et al., 1996; Larrauri and Schmajuk, 2006), the selective modulation of PfC afferent transmission is especially relevant. PfC afferences could facilitate behaviors oriented to specific goals, and a dopamine deficit could be involved in the incapacity to control the behavior (Goto and Grace, 2008).

It should be noted that the dopaminergic innervation of the PfC increases progressively through adolescence until adulthood. In this period, we can find modifications in density, shape and organization of the circuits (Kalsbeek et al., 1988; Benes et al., 2000; Seamans and Yang, 2004; Segalowitz and Davies, 2004; Manitt et al., 2011; Naneix et al., 2012). A mature circuit allows the dopaminergic neurons to fit their responses in an adaptive way, modulating their response in correlation with environmental changes (Spear, 2000; Tseng and O'Donnell, 2004, 2007; O’Donnell, 2011; Cass et al., 2013; Godsil et al., 2013). Currently, it is estimated that delays or alterations in the maturation process of the PfC dopamine system could be the cause of a large number of mental disorders (O'Donnell, 2011; Godsil et al., 2013). Specifically, a poor inhibitory capacity of the PfC over the NAc may be the major etiological factor in severe disorders such as schizophrenia. In fact, a deficit in the response to the pulse has been observed in different types of cognitive disorders, and it is specifically relevant in patients with schizophrenia (Braff et al., 1992, 2001a,b). Thus, a reduced PPI could be used as a trait for attentional deficit, besides being included as a schizotypy personality trait or a possible endophenotype of schizophrenia (Cadenhead et al., 2000; Braff, 2010; O’Donnell, 2011).

However, this trait is not specific for patients with schizophrenia but indicates a trait of vulnerability, and it is very clear in patients with schizophrenia. In this regard, the PPI deficit could be a necessary condition as a risk factor of schizophrenia, but it could not be sufficient by itself. The PPI deficit might be found in several disorders, and a pathological process such as schizophrenia needs other indicators. 


\section{PPI, DOPAMINE AND IMPULSIVITY: A TRAIT, A NEUROTRANSMITTER AND A QUANTIFIABLE MEASURE NOT ASSOCIATED EXCLUSIVELY WITH SCHIZOPHRENIA}

PPI is an easy system to measure in animals including humans. It has been used in animal models of schizophrenia, even though there are several studies where this procedure has been correlated with impulsivity traits. López et al. (2015) analyzed the PPI in rats classified as impulsive by an autoshaping procedure. Animals designated as sign trackers showed approach behavior to a conditional stimulus before delivery of unconditional stimulus. Specifically, for sign tracker animals (STa) the conditional stimulus could be a surrogate of the unconditional stimulus (Flagel et al., 2007; Robinson and Flagel, 2009). These kind of animals showed high levels of dopamine in NAc, but only in the presence of a conditional stimulus (Flagel et al., 2011). These data were consistent with the results of López et al. (2015) using a PPI procedure. In fact, the STa showed a lower PPI response to stimuli of low intensity. This reduced inhibitory ability of the STa showed a difference in the behavioral pattern in normal animals. Furthermore, these data may indicate that ST subjects may be more vulnerable to cognitive disorders in which dopamine is involved.

An important question about the vulnerability of STa to an impulsive behavior comes from specific activity of D2 subtype dopamine receptor. This receptor is located presynaptically on PfC terminals, and has been related with a selective modulation of the NAc to facilitate goal-directed behaviors (Goto and Grace, 2008). In addition, several psychopathologies associated with PfC have shown a deficit between this structure and the projections to NAc (O’Donnell, 2011). López et al. (2015) found a possible vulnerability from STa, since these animals showed a large sensibility of D2 receptor to the administration of an agonist such as quinpirole. This drug affected only STa performance, indicating that this type of trait differs from that observed in schizophrenia. It would be appropriate at this stage to point out the difference between an animal model of impulsivity and an animal model of schizophrenia regarding a dysfunction in PfC. These models have developed several protocols to evaluate attentional processes, and $\mathrm{LI}$ is a perfect candidate to discriminate between impulsivity and schizophrenia, because it allows for evaluating attention and executive functions, both specific to PfC function. Impulsive models of animals have found differences in incentive salience of the conditional stimulus, but not in attentional problems (Berridge and Robinson, 1998; Berridge, 2007) such as in schizophrenia models.

\section{LI, DOPAMINE AND ATTENTIONAL DEFICITS}

LI is a learning process observed when the acquisition of a conditional response to a conditioned stimulus paired with a reinforcer is retarded if the same stimulus has previously been pre-exposed in the absence of the reinforcer. LI pharmacology has been associated almost exclusively with the use of an animal model of schizophrenia, and is therefore largely consistent with the pharmacology of schizophrenia (Lubow and Kaplan, 2010; Lubow and Weiner, 2010; Díaz et al., 2015). Specifically, because some of the symptoms of schizophrenia are characterized by an inability to filter, or ignore irrelevant or unimportant stimuli, an anomalous LI was proposed as a tool for the study of possible deficits of attention (Lubow and Weiner, 2010).

Again, dopaminergic activity of the NAc is the essential neural substrate for its expression. Animal models have shown that the primary role of the NAc is to restrict the expression of LI under certain conditions, and thus ensure that the LI is flexible and sensitive to environmental demands. It is important to highlight that, in the absence of modulator mechanisms responsible for restricting the expression of LI to the specific conditions, the effects of an irrelevant stimulus would be extremely robust and maladaptive. In this regard, LI might reflect the psychological processes that are impaired in schizophrenia, since most of the patients showed a reduced expression of this phenomenon. The identification of brain regions whose damage leads to disrupt the LI, joined with the studies of different parameters of expression in animal models, can provide important information on the dysfunctional brain circuits in schizophrenia. In previous decades it was suggested that some kind of hyperactivity of the dopaminergic systems represent a primary biochemical alteration in schizophrenia, which apparently constituted at least a plausible justification for biochemical alteration in this disorder (Iversen, 1976).

To gain insight into quantifiable attentional processes in LI, Díaz et al. (2014) analyzed the effect of various types of pre-exposure to a stimulus. The results indicated that there is a transfer from the ventral to the dorsal striatum in the processing of environmental information. In addition, the dorsomedial striatum is key to encode stimuli when these become irrelevant due to the lack of consequences after their presentation. A deficit in PfC could be the cause of a loss of transfer from ventral to dorsal striatum. Currently there are some laboratories working on this possibility. The inability to modulate dopamine in NAc does not allow for attentional disengagement, showing a persistent state of continuous attention.

The inability of encoding irrelevant information is one of the clearest deficits observed in patients with schizophrenia. Many modern learning theories assume that the amount of attention to a signal depends on how well the signal predicts the significant event of the past. Schizophrenia is associated with attention deficit and recent theories of psychosis have argued that positive symptoms such as delusions and hallucinations are related to a lack of selective attention. Patients with schizophrenia, who had severe positive symptoms, showed a clear difficulty in discriminating between predictive and non-predictive cues when compared to healthy adults. In addition, the rate of learning about non-predictive signals correlated with more severe positive symptoms in schizophrenia. These results suggest that the positive symptoms of schizophrenia were associated with increased attention, both to signals that are likely to be predictive and to those that are not predictive for causal learning. This 
selective attention deficit was the result of learning irrelevant causal associations (Morris et al., 2013). In this regard, the development of specific protocols to differentiate the expression of LI could be used as a possible risk factor in the population.

However, the complexity of this disorder suggests the possibility of different etiological factors may underlie the disease. At present there are many contradictory results regarding whether IL is affected in schizophrenia. Lubow and Kaplan (2010) addressed this issue in a recent review. They emphasize the difference between positive and negative symptoms in relation to the expression of IL. For instance, patients with high levels of negative symptoms and low of positive showed a potentiated LI. This data is relevant, because they could be observing different symptoms of the illness or different illness.

\section{CONCLUDING REMARKS}

The mesocortical input of dopamine and the PfC play a critical role in normal cognitive processes and in several neuropsychiatric diseases. This dopamine input regulates aspects of working memory, planning and attention, among others. Similarly, some disturbances may be the basis for a variety of positive and negative symptoms, and therefore of many of the cognitive deficits associated with mental illness. Despite intensive research, we still have a lack of understanding of the basic principles of dopamine activity in the PfC and all the mesolimbic system. In recent years, there has been considerable effort to understand the cellular mechanisms of modulation of dopamine neurons in the PfC and its relationship with behavior. However, the results of these efforts have often led to contradictions and disputes (Nieoullon, 2002). Given the complexity of the

\section{REFERENCES}

Bachevalier, J., Alvarado, M. C., and Malkova, L. (1999). Memory and socioemotional behavior in monkeys after hippocampal damage incurred in infancy or in adulthood. Biol. Psychiatry 46, 329-339. doi: 10.1016/S00063223(99)00123-7

Benes, F. M., Taylor, J. B., and Cunningham, M. C. (2000). Convergence and plasticity of monoaminergic systems in the medial prefrontal cortex during the postnatal period: implications for the development of psychopathology. Cereb. Cortex 10, 1014-1027. doi: 10.1093/cercor/10. 10.1014

Berridge, K. (2007). The debate over dopamine's role in reward: the case for incentive salience. Psychopharmacology 191, 391-431. doi: 10.1007/s00213-0060578-x

Berridge, K. C., and Robinson, T. E. (1998). What is the role of dopamine in reward: hedonic impact, reward learning, or incentive salience? Brain Res. Rev. 28, 309-369. doi: 10.1016/S0165-0173(98)00019-8

Brady, A. M., McCallum, S. E., Glick, S. D., and O’Donnell, P. (2008). Enhanced methamphetamine self-administration in a neurodevelopmental rat model of schizophrenia. Psychopharmacology 200, 205-215. doi: 10.1007/s00213-0081195-7

Braff, D., Geyer, M., Light, G., Sprock, J., Perry, W., Cadenhead, K., et al. (2001a). Impact of prepulse characteristics on the detection of sensorimotor gating deficits in schizophrenia. Schizophr. Res. 49, 171-178. doi: 10.1016/S09209964(00)00139-0

Braff, D. L., Geyer, M. A., and Swerdlow, N. R. (2001b). Human studies of prepulse inhibition of startle: normal subjects, patient groups, and pharmacological studies. Psychopharmacology 156, 234-258. doi: 10.1007/s002130100810 function of the mesolimbic and the dopaminergic systems, the development of new tools will be necessary to facilitate discrimination of diagnostics and to provide a more objective assessment of the current classification systems. Namely, we suggest a shift or reconsideration in diagnostic scales adding other indicators. Clinical psychology has many tools to evaluate PfC dysfunction (for a review see Gruszka et al., 2010). We propose that PPI and LI could help to develop a new classification system, where we could distinguish between a psychotic illness such as schizophrenia by a dysfunction in PfC dopamine from other types of schizophrenia included in current scales. As we indicated above, current classification systems could be considering a diverse group of disorders under the same term of schizophrenia illness, and the different combination of positive and negative symptoms could indicate the severity of the disorder. The in depth analysis of these mechanisms, combined with genetic factors, is a new view that could facilitate the development of diagnostic categories in a more specific way and, therefore, a new therapeutic perspective in the future.

\section{AUTHOR CONTRIBUTIONS}

All authors contributed similarly in the theoretical development of the manuscript.

\section{FUNDING}

This research was supported by Ministerio de Economía y Competitividad (PSI2012- 32445 grant).

Braff, D. L. (2010). Prepulse inhibition of the startle reflex: a window on the brain in schizophrenia. Curr. Top Behav. Neurosci. 4, 349-371. doi: 10.1007/7854_2010_61

Braff, D. L., Grillon, C., and Geyer, M. A. (1992). Gating and habituation of the startle reflex in schizophrenic patients. Arch. Gen. Psychiatry 49, 206-215. doi: 10.1001/archpsyc.1992.01820030038005

Braff, D. L., and Swerdlow, N. R. (1997). Neuroanatomy of schizophrenia. Schizophr. Bull. 23, 509-512. doi: 10.1093/schbul/23.3.509

Bramon, E., Walshe, M., McDonald, C., Martín, B., Toulopoulou, T., Wickham, H., et al. (2005). Dermatoglyphics and schizophrenia: a meta-analysis and investigation of the impact of obstetric complications upon a-b ridge count. Schizophr. Res. 75, 399-404. doi: 10.1016/j.schres.2004.08.022

Cadenhead, K. S., Light, G. A., Geyer, M. A., and Braff, D. L. (2000). Sensory gating deficits assessed by the P50 event-related potential in subjects with schizotypal personality disorder. Am. J. Psychiatry 157, 55-59. doi: 10.1176/ajp.157.1.55

Cass, D. K., Thomases, D. R., Caballero, A., and Tseng, K. Y. (2013). Developmental disruption of gamma-aminobutyric acid function in the medial prefrontal cortex by noncontingent cocaine exposure during early adolescence. Biol. Psychiatry 74, 490-501. doi: 10.1016/j.biopsych.2013.02.021

Chambers, R. A., and Lipska, B. K. (2011). "A method to the madness: producing the neonatal ventral hippocampal lesion rat model of schizophrenia," in Animal Models of Schizophrenia and Related Disorders, ed. P. O'Donnell (New York: Humana Press), 1-24.

Chambers, R. A., Moore, J., McEvoy, J. P., and Levin, E. D. (1996). Cognitive effects of neonatal hippocampal lesions in a rat model of schizophrenia. Neuropsychopharmacology 15, 587-594. doi: 10.1016/S0893-133X(96)00132-7

Díaz, E., Medellín, J., Sánchez, N., Vargas, J. P., and López, J. C. (2015). Involvement of D1 and D2 dopamine receptor in the recovery processes of stimuli in 
latent inhibition. Psychopharmacology 232, 4337-4346. doi: 10.1007/s00213015-4063-2

Díaz, E., Vargas, J. P., Quintero, E., de la Casa, L. G., O’Donnell, P., and López, J. C. (2014). Differential implication of dorsolateral and dorsomedial striatum in encoding and recovery processes of latent inhibition. Neurobiol. Learn. Mem. 111, 19-25. doi: 10.1016/j.nlm.2014.02.008

Ellenbroek, B. A., Budde, S., and Cools, A. R. (1996). Prepulse inhibition and latent inhibition: the role of dopamine in the medial prefrontal cortex. Neuroscience 2, 535-542. doi: 10.1016/0306-4522(96)00307-7

Featherstone, R. E., Rizos, Z., Nobrega, J. N., Kapur, S., and Fletcher, P. J. (2007). Gestational methylazoxymethanol acetate treatment impairs select cognitive functions: parallels to schizophrenia. Neuropsychopharmacology 32, 483-492. doi: $10.1038 /$ sj.npp.1301223

Feldman, R. S., Meyer, J. S., and Quenzer, L. F. (1997). Principles of Neuropsychopharmacology. Sunderland, MA: Sinauer Associates Inc.

Flagel, S. B., Clark, J. J., Robinson, T. E., Mayo, L., Czuj, A., Willuhn, I., et al. (2011). A selective role for dopamine in stimulus-reward learning. Nature 469, 53-57. doi: 10.1038/nature09588

Flagel, S. B., Watson, S. J., Robinson, T. E., and Akil, H. (2007). Individual differences in the propensity to approach signals vs goals promote different adaptations in the dopamine system of rats. Psychopharmacology 191, 599-607. doi: 10.1007/s00213-006-0535-8

Flagstad, P., Glenthoj, B. Y., and Didriksen, M. (2005). Cognitive deficits caused by late gestational disruption of neurogenesis in rats: a preclinical model of schizophrenia. Neuropsychopharmacology 30, 250-260. doi: 10.1038/sj.npp. 1300625

Flagstad, P., Mork, A., Glenthoj, B. Y., Van Beek, J., Michael-Titus, A. T., and Didriksen, M. (2004). Disruption of neurogenesis on gestational day 17 in the rat causes behavioral changes relevant to positive and negative schizophrenia symptoms and alters amphetamine-induced dopamine release in nucleus accumbens. Neuropsychopharmacology 29, 2052-2064. doi: $10.1038 /$ si.npp. 1300516

Floresco, S. B., Todd, C. L., and Grace, A. A. (2001). Glutamatergic afferents from the hippocampus to the nucleus accumbens regulate activity of ventral tegmental area dopamine neurons. J. Neurosci. 21, 4915-4922.

Frances, A. J., and Widiger, T. (2012). Psychiatric diagnoses: lessons learned from the DSM-IV past and cautions for the DSM-5 future. Annu. Rev. Clin. Psychol. 8, 109-130. doi: 10.1146/annurev-clinpsy-032511-143102

Godsil, B. P., Kissc, J. P., Spedding, M., and Jay, T. M. (2013). The hippocampal-prefrontal pathway: the weak link in psychiatric disorders? Eur. Neuropsychopharmacol. 23, 1165-1181. doi: 10.1016/j.euroneuro.2012. 10.018

Goldman, D. (2012). Our Genes, Our Choices: How Genotype and Gene Interactions Affect Behavior. Waltham, MA: Academic Press.

Goto, Y., and Grace, A. (2008). Limbic and cortical information processing in the nucleus accumbens. Trends Neurosci. 31, 552-558. doi: 10.1016/j.tins.2008.08.002

Gottesman, I. I., and Shields, J. (1972). Schizophrenia and Genetics: A Twin Study Vantage Point. New York: Academic Press.

Gottesman, I. I., and Shields, J. (1973). Genetic theorizing and schizophrenia. Br. J. Psychiatry 122, 15-30. doi: 10.1192/bjp.122.1.15

Grace, A. A. (2000). Gating of information flow within the limbic system and the pathophysiology of schizophrenia. Brain Res. 31, 331-342. doi: 10.1016/S01650173(99)00049-1

Grace, A. A., and Sesack, S. (2010). The cortico-basal ganglia reward network: microcircuitry. Neuropsychopharmacology 3, 4-26. doi: 10.1038/npp. 2009.93

Graham, F. K. (1975). The more or less startling effects of weak prestimulation. Psychophysiology 12, 238-248. doi: 10.1111/j.1469-8986.1975. tb01284.x

Groenewegen, H. G., Wright, C. I., Beijer, V. J., and Voorn, P. (1999). Convergence and segregation of ventral striatal inputs and outputs. Ann. N. Y. Acad. Sci. 877, 49-64. doi: 10.1111/j.1749-6632.1999.tb09260.x

Gruszka, A., Hampshire, A., and Owen, A. M. (2010). "Learned irrelevance revisited: pathology-based individual differences, normal variation and neural correlates," in Handbook of Individual Differences in Cognition, Attention, Memory, and Executive Control, eds A. Gruszka, G. Matthews, and B. Szymura (New York, NY: Springer), 127-143.
Hasler, G., Drevets, W. C., Gould, T. D., Gottesman, I. I., and Janji, H. K. (2006). Toward constructing an endophenotype strategy for bipolar disorders. Biol. Psychiatry 60, 93-105. doi: 10.1016/j.biopsych.2005.11.006

Hazane, F., Krebs, M. O., Jay, T. M., and Le Pen, G. (2009). Behavioral perturbations after prenatal neurogenesis disturbance in female rat. Neurotox. Res. 15, $311-$ 320. doi: 10.1007/s12640-009-9035-z

Hyman, S. E. (2010). Diagnosis of mental disorders: the problem of reification. Annu. Rev. Clin. Psychol. 6, 155-179. doi: 10.1146/annurev.clinpsy.3.022806.091532

Iversen, L. (1976). Dopamine in the brain and its possible role in madness. Trends Biochem. Sci. 1, 121-123. doi: 10.1016/0968-0004(76) 90027-X

Kalsbeek, A., Voorn, P., Buijs, R. M., Pool, C. W., and Uylings, H. B. (1988). Development of the dopaminergic innervation in the prefrontal cortex of the rat. J. Comp. Neurol. 269, 58-72. doi: 10.1002/cne.902 690105

Kidd, K. K. (1997). Can we find genes for schizophrenia? Am. J. Med. Genet. 74, 104-111. doi: 10.1002/(SICI)1096-8628(19970221)74:1<104::AIDAJMG21 > 3.0.CO;2-U

Larrauri, J., and Schmajuk, N. (2006). "Prepulse inhibition mechanisms and cognitive processes: a review and model," in Neurotransmitter Interactions and Cognitive Function, ed. E. D. Levin (Basel: Birkhäuser Verlag), 245-278.

Le Pen, G., Bellon, A., Krebs, M. O., and Jay, T. M. (2011). "Gestational MAM (Methylazoxymethanol) administration: a promising animal model for psychosis onset," in Animal Models of Schizophrenia and Related Disorders, ed. P. O'Donnell (New York: Humana Press), 25-77.

Le Pen, G., Gourevitch, R., Hazane, F., Hoareau, C., Jay, T. M., and Krebs, M. O. (2006). Peripubertal maturation after developmental disturbance: a model for psychosis onset in the rat. Neuroscience 143, 395-405. doi: 10.1016/j.neuroscience.2006.08.004

Lipska, B. K., Aultman, J. M., Verma, A., Weinberger, D. R., and Moghaddam, B. (2002). Neonatal damage of the ventral hippocampus impairs working memory in the rat. Neuropsychopharmacology 27, 47-54. doi: 10.1016/S0893$133 \mathrm{X}(02) 00282-8$

Lipska, B. K., Jaskiw, G. E., and Weinberger, D. R. (1993). Postpubertal emergence of hyperresponsiveness to stress and to amphetamine after neonatal excitotoxic hippocampal damage: a potential animal model of schizophrenia. Neuropsychopharmacology 90, 67-75. doi: 10.1038/npp. 1993.44

López, J. C., Karlsson, R. M., and O’Donnell, P. (2015). Dopamine D2 modulation of sign and goal tracking in rats. Neuropsychopharmacology 40, 2096-2102. doi: 10.1038/npp.2015.68

Lubow, R. E., and Gewirtz, J. C. (1995). Latent inhibition in humans: data, theory, and implications for schizophrenia. Psychol. Bull. 117, 87-103. doi: 10.1037/0033-2909.117.1.87

Lubow, R. E., and Kaplan, O. (2010). "Psychopathology and individual differences in latent inhibition: schizophrenia and schizotypality," in Handbook of Individual Differences in Cognition. Attention, Memory, and Executive Control, eds A. Gruszka, G. Matthews, and B. Szymura (New York, NY: Springer), 181-193.

Lubow, R. E., and Weiner, I. (2010). "Issues in latent inhibition research and theory," in Latent Inhibition Cognition, Neuroscience and Applications to Schizophrenia, eds R. E. Lubow and I. Weiner (Cambridge: Cambridge University Press), 531-557.

Lüthy, M., Blumenthal, T., Langewitz, W., Kiss, A., Keller, U., and Schächinger, H. (2003). Prepulse inhibition of the human startle eye blink response by visual food cues. Appetite 41, 191-195. doi: 10.1016/S0195-6663(03) 00080-1

Manitt, C., Mimee, A., Eng, C., Pokinko, M., Stroh, T., Cooper, H. M., et al. (2011). The netrin receptor DCC is required in the pubertal organization of mesocortical dopamine circuitry. J. Neurosci. 31, 8381-8394. doi: 10.1523/JNEUROSCI.0606-11.2011

Manoach, D. S. (2003). Prefrontal cortex dysfunction during working memory performance in schizophrenia: reconciling discrepant findings. Schizophr. Res. 60, 285-298. doi: 10.1016/S0920-9964(02) 00294-3

Marquis, J. P., Goulet, S., and Dore, F. Y. (2008). Neonatal ventral hippocampus lesions disrupt extra-dimensional shift and alter dendritic spine density in the 
medial prefrontal cortex of juvenile rats. Neurobiol. Learn. Mem. 90, 339-346. doi: $10.1016 /$ j.nlm.2008.04.005

Milad, M. R., and Rauch, S. L. (2012). Obsessive-compulsive disorder: beyond segregated cortico-striatal pathways. Trends Cogn. Sci. 16, 43-51. doi: 10.1016/j.tics.2011.11.003

Miller, G. A., and Rockstroh, B. (2013). Endophenotypes in psychopathology research: where do we stand? Annu. Rev. Clin. Psychol. 9, 177-213. doi: 10.1146/annurev-clinpsy-050212-185540

Missale, C., Russel, N. S., Robinson, M., and Caron, M. (1998). Dopamine receptors: from structure to function. Physiol. Rev. 78, 189-225.

Moldin, S. O. (1997). The maddening hunt for madness genes. Nat. Genet. 17, 127-129. doi: 10.1038/ng1097-127

Moore, H., Jentsch, J. D., Ghajarnia, M., Geyer, M. A., and Grace, A. A. (2006). A neurobehavioral systems analysis of adult rats exposed to methylazoxymethanol acetate on E17: implications for the neuropathology of schizophrenia. Biol. Psychiatry 60, 253-264. doi: 10.1016/j.biopsych.2006.01.003

Moore, H., West, A. R., and Grace, A. A. (1999). The regulation of forebrain dopamine transmission: relevance to the pathophysiology and psychopathology of schizophrenia. Biol. Psychiatry 46, 40-55. doi: 10.1016/S0006-3223(99)00078-5

Morris, R., Griffiths, O., Le Pelle, E., and Weickert, T. (2013). Attention to irrelevant cues is related to positive symptoms in schizophrenia. Schizophr. Bull. 39, 575-582. doi: 10.1093/schbul/sbr192

Morris, S. E., and Cuthbert, B. N. (2012). Research domain criteria: cognitive systems, neural circuits, and dimensions of behavior. Dialogues Clin. Neurosci. $14,29-37$.

Naneix, F., Marchand, A. R., Di Scala, G., Pape, J.-R., and Coutureau, E. (2012). Parallel maturation of goal-directed behavior and dopaminergic systems during adolescence. J. Neurosci. 32, 16223-16232. doi: 10.1523/JNEUROSCI.308012.2012

Nieoullon, A. (2002). Dopamine and the regulation of cognition and attention. Progr. Neurobiol. 67, 53-83. doi: 10.1016/S0301-0082(02)00011-4

O’Donnell, P. (2011). Adolescent onset of cortical disinhibition in schizophrenia: insights from animal models. Schizophr. Bull. 37, 484-492. doi: $10.1093 /$ schbul/sbr028

O’Donnell, P., and Grace, A. A. (1995). Synaptic interactions among excitatory afferents to nucleus accumbens neurons: hippocampal gating of prefrontal cortical input. J. Neurosci. 15, 3622-3639.

O'Donnell, P., and Grace, A. A. (1998). Dysfunctions in multiple interrelated systems as the neurobiological bases of schizophrenic symptom clusters. Schizophr. Bull. 24, 267-283. doi: 10.1093/oxfordjournals.schbul. a033325

Owen, M. J. (2000). Molecular genetic studies of schizophrenia. Brain Res. Rev. 31, 179-186. doi: 10.1016/S0165-0173(99)00035-1

Penschuck, S., Flagstad, P., Didriksen, M., Leist, M., and Michael-Titus, A. T. (2006). Decrease in parvalbumin-expressing neurons in the hippocampus and increased phencyclidine- induced locomotor activity in the rat methylazoxymethanol (MAM) model of schizophrenia. Eur. J. Neurosci. 23, 279-284. doi: 10.1111/j.1460-9568.2005.04536.x

Plomin, R., and Rende, R. (1991). Human behavioral genetics. Annu. Rev. Psychol. 42, 161-190. doi: 10.1146/annurev.ps.42.020191.001113

Robbins, T. W. (1992). Milestone in dopamine research. Semin. Neurosci. 4, 93-97. doi: 10.1016/1044-5765(92)90007-O

Robbins, T. W., and Everitt, B. J. (1996). Neurobehavioural mechanisms of reward and motivation. Curr. Opin. Neurobiol. 6, 228-236. doi: 10.1016/S09594388(96)80077-8

Robbins, T. W., Gillan, C. M., Smith, D. G., Wit, S., and Ersche, K. D. (2012). Neurocognitive endophenotypes of impulsivity and compulsivity: towards dimensional psychiatry. Trends Cogn. Sci. 16, 81-91. doi: 10.1016/j.tics.2011.11.009

Robinson, T. E., and Flagel, S. B. (2009). Dissociating the predictive and incentive motivational properties of reward-related cues through the study of individual differences. Biol. Psychiatry 65, 869-873. doi: 10.1016/j.biopsych.2008. 09.006

Sams-Dodd, F., Lipska, B. K., and Weinberger, D. R. (1997). Neonatal lesions of the rat ventral hippocampus result in hyperlocomotion and deficits in social behavior in adulthood. Psychopharmacology 132, 303-310. doi: $10.1007 /$ s002130050349
Seamans, J. K., and Yang, C. R. (2004). The principal features and mechanisms of dopamine modulation in the prefrontal cortex. Prog. Neurobiol. 74, 1-58. doi: 10.1016/j.pneurobio.2004.10.002

Seeman, P., and Nizkik, H. B. (1990). Dopamine receptors and transporters in Parkinson's disease and schizophrenia. FASEB J. 4, 2737-2744.

Segalowitz, S. J., and Davies, P. L. (2004). Charting the maturation of the frontal lobe: an electrophysiological strategy. Brain Cogn. 55, 116-133. doi: 10.1016/S0278-2626(03)00283-5

Silver, H., Feldman, P., Bilker, W., and Gur, R. C. (2003). Working memory deficit as a core neuropsychological dysfunction in schizophrenia. Am. J. Psychiatry 160, 1809-1816. doi: 10.1176/appi.ajp.160.10.1809

Simpson, E. H., Kellendonk, C., and Kandel, E. (2010). A possible role for the striatum in the pathogenesis of the cognitive symptoms of schizophrenia. Neuron 65, 585-596. doi: 10.1016/j.neuron.2010.02.014

Spear, L. P. (2000). The adolescent brain and age-related behavioral manifestations. Neurosci.Biobehav. Rev. 24, 417-463.

Swerdlow, N. R., Braff, D. L., Hartston, H., Perry, W., and Geyer, M. A. (1996). Latent inhibition in schizophrenia. Schizophr. Res. 20, 91-103. doi: 10.1016/0920-9964(95)00097-6

Swerdlow, N. R., Halim, N., Hanlon, F. M., Platten, A., and Auerbach, P. P. (2001). Lesion size and amphetamine hyperlocomotion after neonatal ventral hippocampal lesions: more is less. Brain Res. Bull. 55, 71-77. doi: 10.1016/S0361-9230(01)00492-0

Swerdlow, N. R., Lipska, B. K., Weinberger, D. R., Braff, D. L., Jas-kiw, G. E., and Geyer, M. A. (1995). Increased sensitivity to the sensorimotor gatingdisruptive effects of apomorphine after lesions of medial prefrontal cortex or ventral hippocampus in adult rats. Psychopharmacology 122, 27-34. doi: 10.1007/BF02246438

Torrey, E. F., and Yolken, R. H. (2000). Familial and genetic mechanisms in schizophrenia. Brain Res. Rev. 31, 113-117. doi: 10.1016/S0165-0173(99)00028-4

Tseng, K. Y., and O'Donnell, P. (2004). Dopamine-glutamate interactions controlling prefrontal cortical pyramidal cell excitability involve multiple signalling mechanisms. J. Neurosci. 24, 5131-5139. doi: 10.1523/JNEUROSCI.1021-04.2004

Tseng, K.-Y., and O’Donnell, P. (2007). Dopamine modulation of prefrontal cortical interneurons changes during adolescence. Cereb. Cortex 17, 1235-1240. doi: 10.1093/cercor/bhl034

Turetsky, B. I., Calkins, M. E., Light, G. A., Olincy, A., Radant, A. D., and Swerlow, N. R. (2007). Neurophysiological endophenotypes of schizophrenia: the viability of selected candidate measures. Schizophr. Bull. 33, 69-94. doi: $10.1093 / \mathrm{schbul} / \mathrm{sbl} 1060$

Vaidyanathan, U., Malone, S. M., Miller, M. B., Mcgue, M., and Iacono, W. G. (2014). Heritability and molecular genetic basis of acoustic startle eye blink and affectively modulated startle response: a genome-wide association study. Psychophysiology 51, 1285-1299. doi: 10.1111/psyp.12348

Waddington, J. L., Lane, A., Larkin, C., and O'Callaghan, E. (1999). The neurodevelopmental basis of schizophrenia: clinical clues from cerebrocraniofacial dysmorphogenesis, and the roots of a lifetime trajectory of disease. Biol. Psychiatry 46, 31-39. doi: 10.1016/S0006-3223(99) 00055-4

Wan, R. Q., Giovanni, A., Kafka, S. H., and Corbett, R. (1996). Neonatal hippocampal lesions induced hyperresponsiveness to amphetamine: behavioral and in vivo microdialysis studies. Behav. Brain Res. 78, 211-223. doi: 10.1016/0166-4328(95)00251-0

Weiner, I. (2003). The "two-headed" latent inhibition model of schizophrenia: modeling positive and negative symptoms and their treatment. Psychopharmacology 169, 257-297. doi: 10.1007/s00213-002-1313-x

Winokur, G., and Kadrmas, A. (1989). A polyepisodic course in bipolar illness: possible clinical relationships. Comparat. Psychiatry 30, 121-127. doi: 10.1016/0010-440X(89)90063-1

Wise, R. A. (2010). Roles for nigrostriatal -not just mesocorticolimbicdopamine in reward and addiction. Trends Neurosci. 32, 517-524. doi: 10.1016/j.tins.2009.06.004

Wong, E. H., Yocca, F., Smith, M. A., and Lee, C. M. (2010). Challenges and opportunities for drug discovery in psychiatric disorders: the drug hunters' perspective. Int. J. Neuropsychopharmacol. 13, 1269-1284. doi: $10.1017 /$ S1461145710000866 
Zahn-Waxler, C., Mayfíeld, A., Radke-Yarrow, M., McKnew, D. H., Cytryn, L., and Davenport, Y. B. (1988). A follow-up investigation of offspríng of parents with bipolar disorder. Am. J. Psychiatry 145, 506-509. doi: 10.1176/ajp.145.4.506

Conflict of Interest Statement: The authors declare that the research was conducted in the absence of any commercial or financial relationships that could be construed as a potential conflict of interest.
Copyright (c) 2016 Vargas, Díaz, Portavella and López. This is an open-access article distributed under the terms of the Creative Commons Attribution License (CC BY). The use, distribution or reproduction in other forums is permitted, provided the original author(s) or licensor are credited and that the original publication in this journal is cited, in accordance with accepted academic practice. No use, distribution or reproduction is permitted which does not comply with these terms. 